given (30 mg./kg. body-weight) is more effective than is Ambilhar given at a dose of $25 \mathrm{mg}$. $/ \mathrm{kg}$. body-weight for five days.

\section{Summary and Conclusions}

Ambilhar, a nitrothiazole derivative, was given in a dose of $25 \mathrm{mg} . / \mathrm{kg}$. body-weight/day for five days to children and adults excreting eggs of Schistosoma mansoni.

Comparison of the results from adults and children matched for egg output show that adults were more readily "cured" than children, and there was evidence that cure was less likely in heavily infected children.

It is considered that the results of the present trials emphasize the necessity for quantitative studies of egg output to be made in trials of schistosomicidal drugs, and the need for caution in interpreting "cure rates" from drug trials in adults in endemic areas and from patients with light infections. In the absence of cure, the percentage reduction in egg load may provide data of antischistosomal activity.
It is suggested that the dose of Ambilhar was insufficient to produce satisfactory cure rates, but with the comparatively low incidence of side-effects (Jordan, 1966a), particularly among children, the dose can probably be increased with the expectation of better results.

Acknowledgments are made to the Secretary-General, East African Common Services Organization, for permission to publish this work.

\section{REFERENCES}

Bell, D. R. (1963). Bull. Wld Hlth Org., 29, 525. (1964). Ann. trop. Med. Parasit., 58, 219. (1965). Proc. Centr. Afr. Sci. Med. Congr., Lusaka, 1963. Pergamon, London.

Bradley, D. J. (1963). E. Afr. med. F., 40, 240.

Hunter, G. W., Hodges, E. P., Jahnes, W. G., Diamond, L. S., and Ingalls, J. W., jun. (1948). Bull. U.S. Army med. Dep., 8, 128

Jordan, P. (1966a). Acta trop. (Basel). In press. (1966). Bull. Wld Hlth Org. In press.

- and Randall, Kae (1962). Trans. roy. Soc. trop. Med. Hyg., 56, 523.

Lambert, C. R. (1964). Ann. trop. Med. Parasit., 58, 292.

Newsome, J. (1962). Nature (Lond.), 195, 1175.

\title{
Ulcerative Colitis and Finger-clubbing*
}

\author{
J. R. YOUNG, $†$ M.B., B.S.
}

Brit. med. F., 1966, 1, 278-279

A number of investigations into the aetiology of finger-clubbing have been carried out. Some authors have suggested that the vagus nerve is implicated, since most of the diseases with which finger-clubbing is associated involve tissues innervated by this nerve and also because section of the vagus nerve supply to these tissues can be followed by the disappearance of the clubbing. Flavell (1956) observed its disappearance after hilar dissection of the vagus nerve performed to relieve the symptoms of hypertrophic pulmonary osteoarthropathy in three patients with inoperable bronchogenic carcinoma. Exploratory thoracotomy alone in two other patients with the same pathology had no effect on finger-clubbing. Similar findings were reported by Holling et al. (1961), who, in addition, recorded that ligation of the arterial supply to a pulmonary malignant lesion without dissection of the vagus nerve at the hilum had no effect on finger-clubbing. The large bowel is interesting in that it is innervated by the vagus nerve only as far as two-thirds of the distance across the transverse colon-that is, the part developing from the mid-gut (Gray's Anatomy, 1962). Thus, if the vagus is the afferent part of a neural reflex in the pathogenesis of finger-clubbing, the length of bowel affected by ulcerative colitis will have an influence on the presence or absence of fingerclubbing.

Diseases of the gut with which finger-clubbing has been associated are: ulcerative colitis (Schlicke and Bargen, 1940; Mendlowitz, 1942 ; Honska et al., 1957), multiple polyposis (Brulé and Lièvre, 1932 ; Bensaude et al., 1932), chronic bacillary dysentery (Mendlowitz, 1941), amoebic dysentery (Brulé et al., 1937), regional enteritis, tuberculosis, Hodgkin's disease, carcinoma, and sprue (Mendlowitz, 1942), ascariasis (van Creveld, 1931), duodenal ulcer with pyloric stenosis (Dennig, 1901), and idiopathic steatorrhoea (Bennett et al., 1932). All these diseases involve tissues with a vagus nerve supply. Moulonguet and Salomon (1932) did, however, describe two cases of finger-clubbing associated with inflammatory stricture

\footnotetext{
- Based on a paper read at a meeting of the Association of Physicians of Area No. 1 on 17 July 1965.

t Registrar, Department of Radiology, Royal Victoria Infirmary, Newcastle upon Tyne.
}

of the rectum, but, although they excluded coexisting chest disease as a cause of the clubbing, they did not demonstrate the extent of the colonic disease.

The present study was undertaken in order to try to establish the relation between finger-clubbing and the extent of colonic involvement in patients with ulcerative colitis.

\section{Material and Method}

All case reports of patients admitted to the Royal Victoria Infirmary, Newcastle upon Tyne, over the past 10 years with a diagnosis of ulcerative colitis were examined. The criteria for inclusion in the study were: (1) the patient must have had a barium-enema examination or a laparotomy at which the extent of colonic involvement was determined and histological confirmation of the diagnosis obtained; (2) the case report must have included a definite statement as to the presence or absence of finger-clubbing; and (3) the patient must have had a chest $x$-ray examination showing that no intrathoracic disease was present.

The 156 patients who fulfilled the above criteria were divided into two groups: (1) those with ulcerative colitis involving the whole colon or the part of the colon innervated by the vagus nerve, and (2) those with the disease limited to the distal colon, not innervated by the vagus nerve. The number of patients with and without finger-clubbing was recorded within each group.

\section{Results}

Of the 77 patients in group 1, seven were affected by fingerclubbing, whereas no single case of it was found among the 79 patients in group 2 . The probability of the finger-clubbing in the seven patients in group 1 and the absence of it in all patients in group 2 being a chance occurrence is 1 in 128 $(P=0.008)$.

Among the patients with finger-clubbing two had a fulminating course followed by death within one month and eight months respectively of the onset of symptoms of ulcerative 
colitis. The post-mortem examinations revealed extensive changes involving the whole of the large bowel.

The duration of symptoms in the 156 patients varied from 1 month to 35 years. Both extremes were found in the patients with finger-clubbing.

\section{Discussion}

Despite inaccuracies, which are difficult to avoid in retrospective studies of this kind, the analysis shows a significant relation between the presence of finger-clubbing and ulcerative colitis with involvement of the part of the large bowel supplied by the vagus nerve. In view of the fact that this part of the bowel is always involved in severe forms of the disease the possibility that the very severity of the disease is an important factor in the aetiology of finger-clubbing cannot be excluded.

The duration of the disease, on the other hand, seems unlikely to play any important role in the aetiology of fingerclubbing, since this occurred in two patients in our study with a history of only one month and eight months respectively.

The investigation shows that, though there is a relation between finger-clubbing and involvement of the part of the bowel developing from the mid-gut, finger-clubbing is nevertheless a comparatively rare phenomenon. This is in contrast to the impression given by the textbooks that it is a relatively common occurrence in ulcerative colitis.

\section{Summary}

The relation between finger-clubbing and ulcerative colitis has been investigated in a retrospective study of the case histories of 156 patients admitted to the Royal Victoria Infirmary, Newcastle upon Tyne, during the years 1954-64 with a diagnosis of ulcerative colitis.
Finger-clubbing was found to have been present in 7 out of 77 patients in whom the part of the colon supplied by the vagus nerve was involved. Finger-clubbing had not occurred in the 79 patients without involvement of the part mentioned.

Thus the present study would seem to support previous theories implicating the vagus nerve in the pathogenesis of finger-clubbing, though it is impossible to exclude the very severity of ulcerative colitis as a contributing factor in its development.

I wish to thank Dr. H. A. Dewar for his advice and encouragement, Mr. C. F. Naylor and his staff of the Records Department for their co-operation, and Mrs. M. Jackson for editorial assistance.

BIBLIOGRAPHY

Balme, H. W. (1963). Practitioner, 190, 107

Bennett, T. I. Hunter, D., and Vaughan, J. M. (1932). Ouart. F. Med., 1, 603 .

Bensaude, R., Hillemand, P., and Augier, P. (1932). Bull. Soc. méd. Hôp. Paris, 48, 93.

Brit. med. F., 1949, 1, 228.

- 1955, 1, 778.

Brlulé, M., Hillemand, P., and Gaube, R. (1937). Bull. Soc. méd. Hôp. Paris, 53, 55.

- and Lièvre, J.-A. (1932). Ibid., 48, 99.

Dennig, A. (1901). Münch. med. Wschr., 48, 380.

Flavell, G. (1956). Lancet, 1, 260.

Gray's Anatomy (1962). 33rd edition, edited by D. V. Davies and F. Davies, p. 1473. Longmans, London.

Holling, H. E., Brodey, R. S., and Boland, H. C. (1961). Lancet, 2 , 1269.

Honska, W. L., Strenge, H., and Hammarsten, J. F. (1957). Gastroenterology, 33, 489 .

Klinkert, D. (1918). Ned. T. Geneesk., 54, 2041.

Mendlowitz, M. (1941). f. clin. Invest., 20, 113.

- (1942). Medicine (Baltimore), 21, 269

Moulonguet, P., and Salomon, J. (1932). Presse méd., 40, 1269.

Schlicke, C. P., and Bargen, J. A. (1940). Amer. 7. dig. Dis., 7, 17.

van Creveld, S. (1931). Ned. T. Geneesk., 75, 890.

\section{Medical Memoranda}

\section{Female Pseudo-hermaphrodite Presenting with Bilateral Cryptorchidism}

Brit. med. F., 1966, 1, 279-280

The advisability of chromosome investigation of all cases of simple cryptorchidism has been advocated by Ferrier et al. (1963).

The importance of this and other investigations is illustrated by the present report of a phenotypic male child with undescended testes who was subsequently found to have a normal 44XX female karyotype and to be an example of nonadrenal pseudo-hermaphroditism due to the administration of androgens to the mother during pregnancy. The administration of androgenic steroids during early pregnancy as a prophylactic measure in threatened or habitual abortion may lead to varying degrees of virilization; this hazard is emphasized by the large series of such cases previously published (Wilkins et al., 1958; Overzier, 1963). In such cases, the presence of a penile or phallic urethra is a rare phenomenon and this feature, in the present case, had proved extremely misleading and had concealed for many years suspicion of the true genetic sex.
The present case further emphasizes the view already advocated by Dewhurst and Gordon (1963), who report a similar case, that such children must be fully studied within the first year of life.

\section{CASE REPORT}

The child, aged 12 years, was described as a healthy-looking but under-sized boy with bilateral cryptorchidism (Fig. 1). Clinical examination revealed a small but well-formed penis with redundant prepuce. The external urinary meatus was normally situated and there was no chordee; the scrotum was small but not bifid. $\mathrm{He}$ had always been regarded as unmistakably male.

He had attended as an out-patient and as an in-patient on several occasions. Various investigations had been carried out-intravenous pyelogram, cysto-urethrogram, cystometrogram, estimation of 17 ketosteroid excretion-and had shown no abnormality. Exploration of the left inguinal canal had failed to reveal the presence of testis or spermatic cord, buccal smear showed normal female sex chromatin, and chromosome analysis of peripheral blood had shown that the karyotype was $44 \mathrm{XX}$.

His present admission was to allow exploration of the right inguinal canal and to determine the nature of the internal sex organs.

At operation no evidence of testis or cord was found in the right inguinal canal. Laparotomy revealed a well-developed uterus with 